\title{
BMJ Global Health Chagas disease among pregnant Latin American women in the United Kingdom: time for action
}

\author{
Cristina Fernandez Turienzo, ${ }^{1}$ Carmen Cabeza Brasa, ${ }^{2}$ William Newsholme, ${ }^{3}$
} Jane Sandall, ${ }^{1}$ Peter L Chiodini, ${ }^{2,4}$ David A J Moore ${ }^{2,4}$

To cite: Fernandez Turienzo C, Cabeza Brasa C, Newsholme W, et al. Chagas disease among pregnant Latin American women in the United Kingdom: time for action. BMJ Glob Health 2017;2:e000478. doi:10.1136/ bmjgh-2017-000478

Handling editor Alberto GarciaBasteiro

Received 15 July 2017 Revised 31 August 2017 Accepted 25 September 2017

\section{(a) CrossMark}

'Department of Women and Children's Health, King's College, London, UK

${ }^{2}$ Hospital for Tropical Diseases, University College London Hospitals NHS Foundation Trust, London, UK

${ }^{3}$ Department of Infection, Guy's and St Thomas' NHS Foundation Trust, London, UK

${ }^{4}$ Department of Clinical

Research, London School of Hygiene and Tropical Medicine, London, UK

\section{Correspondence to}

Cristina Fernandez Turienzo, Department of Women and Children's Health, King's College London SE1 7EH, UK; cristina.fernandez_turienzo@ kcl.ac.uk

\section{COMMENTARY}

Chagas disease, sometimes referred to as American trypanosomiasis, is an infectious disease caused by the parasite Trypanosoma cruzi $($ T. cruzi) which affects $\sim 7$ million people worldwide. The disease is endemic in Mexico, Central and South America-especially poor rural areas-where it kills more people than any other parasitic infection. ${ }^{1}$ As a result of migration to Europe from Latin America, Chagas disease has been seen with increasing frequency in European countries. ${ }^{2}$ Thus, diagnosis and management of disease and prevention of transmission are an emerging challenge for the National Health Service (NHS) and for the United Kingdom (UK) public health.

To date, Chagas disease has only rarely been reported in the UK but consideration of migration data and the known prevalence of the disease in endemic countries suggests that it is likely that this reflects considerable under-ascertainment. ${ }^{3}$ If the estimated prevalence of $1.3 \%$ among 95500 Latin American (LA) residents in London is correct then at least $95 \%$ of prevalent cases remain undiagnosed. ${ }^{4}$ In London alone there may be more than 130000 LAs if irregular migrants, second-generation LA migrants and LA migrants with citizenship in other European countries are included. ${ }^{5}$

In Latin America, the infection is mostly acquired via the classic vector-borne route of transmission when people come into contact with the faeces of infected triatomine bugs, also known as 'kissing bugs' or 'assassin bugs'. In the UK and other non-endemic areas where the vector is not present, the risk of $T$. cruzi acquisition is via the less common routes of transmission, such as blood transfusion, organ transplantation and vertical transmission from infected mothers. ${ }^{1}$ Vertical transmission occurs in an average of $4.7 \%$ of all

\section{Summary box}

Chagas disease - caused by infection with parasite Trypanosoma cruzi (T. cruzi) - is an emerging but still largely unrecognised parasitic disease in the United Kingdom (UK).

- The classic vector-borne route of transmission by infected triatomine bugs only occurs in the endemic areas of Latin America, but less common routes of transmission - organ transplantations, blood transfusions and vertical transmission-have been reported in Europe.

- The UK has implemented health policy measures to control the transmission, including the systematic screening of at-risk blood and organ donations.

- Determining the prevalence of $T$. cruzi infection in Latin American women living in London remains a key priority to inform evidence-based screening policy and practice.

affected pregnancies, but varies significantly depending on the maternal country of birth. Infants born with congenital Chagas may have a severe and life-threatening disease, although most infections are asymptomatic in early life. ${ }^{7}$ Treatment efficacy rate in congenital cases is very high and therefore, identification of these cases will have the benefit of avoiding further complications of the disease and also the benefit of preventing the transmission. ${ }^{8}$

A review and meta-analysis by RequenaMéndez and colleagues ${ }^{9}$ reported a pooled prevalence of $6.5 \%$ in pregnant LA migrants living in Europe; heterogeneity among studies was high, and migrants from Bolivia had the highest prevalence of the disease. Though pregnant LA women living in the UK are likely to be demographically similar, the prevalence of Chagas in this population is not known, as no routine screening is performed and most children who are infected will follow an asymptomatic clinical course. Nevertheless, 
up to $30 \%-40 \%$ of vertically infected children will suffer cardiac, neurological and/or gastrointestinal disease, up to $5-15$ years after infection. ${ }^{10}$ Heart failure, arrhythmia and cardiomyopathy are the most common cause of death in infected adults. ${ }^{11}$

Potential risk exposure is high. Latin Americans are the second fastest growing non-European migrant population in London. ${ }^{5}$ In 2015 , there were officially more than $54000 \mathrm{LA}$ women of childbearing age living in London and more than 2350 live births from women born in Latin America. ${ }^{12}$ However, estimating the actual size of the pregnant LA population in London is not easy; the country of birth is not routinely documented in maternity notes and electronic records, and LA ethnicity is not recognised in the current UK ethnicity classification or in the antenatal family origin questionnaire used for haemoglobinopathy screening. Additionally, pregnant LA women in London are likely to experience major barriers to accessing healthcare services, and there is very little information on their healthcare needs. ${ }^{13}$

The UK has developed and implemented health policy measures to control the transmission of T. cruzi infection, including the systematic screening of at-risk blood, for which the UK was the first country to implement, ${ }^{14}$ and organ donations. ${ }^{15}$ The Migrant Health Guide, launched by Public Health England (PHE) in 2010 as a resource for health professionals working with migrants, recommends that high-risk women should be offered serological testing as part of their routine antenatal care. ${ }^{3}$ However, it is estimated that 3000 women per year from the affected regions receive maternity care each year in England and $<6 \%$ of these women were tested in 2016 (Chiodini PL, Hospital for Tropical Diseases, personal communication). Thus, the majority of women who might be infected are missing out on the opportunity for diagnosis and if infected, receiving treatment after weaning. Furthermore, their infants are not being investigated for signs of infection. Despite the advice in the Migrant Health Guide, there is currently no routine targeted screening for diagnosis and treatment of vertically infected neonates-an intervention that is recommended by the WHO because of its high treatment efficacy. ${ }^{18}$ Screening programmes for LA migrants in antenatal care units and primary care centres in France, Germany, Italy, Switzerland and Spain have been shown to be cost-effective. ${ }^{1617}$

The international emergence of Chagas disease in LA migrants to non-endemic regions of the world and the silent nature of most cases of vertical transmission have important public health implications for policy-makers and clinicians in the UK. The current PHE recommendation is invisible and not systematically implemented at present. Screening of all at-risk LA women of childbearing age, not just those who are already pregnant, may be a more appropriate strategy, ${ }^{17}$ facilitating preconception antiparasitic treatment which greatly reduces the risk of vertical transmission. A coherent, unified screening strategy to detect and treat congenital Chagas is required in the UK and other non-endemic countries ${ }^{18}$ together with an appropriate epidemiological surveillance system ${ }^{19} 20$ able to evaluate the coverage and the efficiency of the programme.

The PHE recommendation presumably arose from the reasonable assumption that screening in antenatal clinics should be organisationally considerably more straightforward as the structures for screening for a range of infectious and non-infectious conditions are already in place. Lack of an appetite for implementation suggests that a more nuanced approach may therefore be necessary. Determining the prevalence and risk factors for $T$. cruzi infection in LA women living in London is a key priority for informing the design and implementation of the most cost-effective health interventions.

Contributors All authors contributed equally.

Funding CFT and JS are supported by the National Institute for Health Research (NIHR) Collaboration for Leadership in Applied Health Research and Care (CLAHRC) South London at King's College Hospital NHS Foundation Trust. PLC is supported by the NIHR University College London Hospitals Biomedical Research Centre (UCLH $\mathrm{BRC})$. PLC is a member of the WHO non-endemic countries initiative for Chagas disease and a member of the UK Advisory Committee on Dangerous Pathogens. The views expressed are those of the authors and not necessarily those of the NHS, the NIHR or the Department of Health.

\section{Competing interests None declared.}

Provenance and peer review Not commissioned; externally peer reviewed.

Data sharing statement No additional data are available.

Open Access This is an Open Access article distributed in accordance with the Creative Commons Attribution Non Commercial (CC BY-NC 4.0) license, which permits others to distribute, remix, adapt, build upon this work non-commercially, and license their derivative works on different terms, provided the original work is properly cited and the use is non-commercial. See: http://creativecommons.org/ licenses/by-nc/4.0/

(C) Article author(s) (or their employer(s) unless otherwise stated in the text of the article) 2017. All rights reserved. No commercial use is permitted unless otherwise expressly granted.

\section{REFERENCES}

1. World Health Organisation. Chagas disease (American trypanosomiasis). $2016 \mathrm{http}: / /$ www.who.int/mediacentre/factsheets/ fs340/en/ (accessed 2 Nov 2016).

2. Basile L, Jansa JM, Carlier Y, et al. Working Group on Chagas Disease. Chagas disease in European countries: the challenge of a surveillance system. Euro Surveill 2011;16:pii: 19968.

3. Public Health England. Chagas disease: migrant health guide. 2016 https://www.gov.uk/guidance/chagas-disease-migrant-health-guide (accessed 4 Dec 2016).

4. Requena-Méndez A, Moore DA, Subirà C, et al. Addressing the neglect: Chagas disease in London, UK. Lancet Glob Health 2016;4:e231-e233.

5. Mcllwaine C, Bunge D. Towards visibility: the Latin American community in London. London: Trust for LondonThe Latin American community in London trust for London, 2016.

6. Howard EJ, Xion X, Carlier Y, et al. Frequency of the congenital transmission of trypanosoma cruzi: a systematic review and metaanalysis. BJOG 2014;21:22-33.

7. Carlier Y, Torrico F, Sosa-Estani S, et al. Congenital chagas disease: recommendations for diagnosis, treatment and control of newborns, siblings and pregnant women. PLoS Negl Trop Dis 2011;5:e1250.

8. Organización Mundial de la Salud (OMS) Organización Panamericana de la Salud (OPS). ETMI Plus: Marco para la eliminación de la transmisión maternoinfantil del VIH, la sifilis, la hepatitis y la enfermedad de Chagas. Washington: OMS OPS, 2017.

9. Requena-Méndez A, Aldasoro E, de Lazzari E, et al. Prevalence of Chagas disease in Latin-American migrants living in Europe: 
a systematic review and meta-analysis. PLoS Negl Trop Dis 2015;9:e0003540.

10. Rassi A, Rassi A, Marin-Neto JA. Chagas disease. Lancet 2010;375:1388-402.

11. Cucunubá ZM, Okuwoga $O$, Basáñez MG, et al. Increased mortality attributed to Chagas disease: a systematic review and metaanalysis. Parasit Vectors 2016;9:42.

12. Office for National Statistics. Personal communication (Foskett $E$ and Littlefield M). 2016 (accessed 21 Nov 2016).

13. Granada L, Paccoud I. Colaition of Latin Americans in the UK. Latin Americans: a case for better access to sexual health services. London, UK: NAZ Project, 2014.

14. Kitchen AD, Hewitt PE, Chiodini PL. The early implementation of Trypanosoma cruzi antibody screening of donors and donations within England: preempting a problem. Transfusion 2012;52:1931-9.

15. Requena-Méndez A, Albajar-Viñas P, Angheben A, et al. Health policies to control Chagas disease transmission in European countries. PLoS Negl Trop Dis 2014;8:e3245.
16. Sicuri E, Muñoz J, Pinazo MJ, et al. Economic evaluation of chagas disease screening of pregnant Latin American women and of their infants in a non endemic area. Acta Trop 2011;118:110-7.

17. Requena-Méndez A, Bussion S, Aldasoro E, et al. Cost-effectiveness of chagas disease screening in Latin American migrants at primary health-care centres in Europe: a Markov model analysis. Lancet Glob Health 2017;5:e439-e447.

18. Navarro M, Monge-Maíllo B, Flores-Chavez MD, et al. Hunting hidden parasites: Trypanosoma cruzi. Lancet 2017;390:724-6.

19. Basile L, Oliveira I, Ciruela P, et al. The current screening programme for congenital transmission of Chagas disease in Catalonia, Spain. Euro Surveill 2011;16:pii: 19972.

20. Barona Vilar C, Giménez Martí MJ, Fraile T, et al. Prevalence of Trypanosoma cruzi infection in pregnant Latin American women and congenital transmission rate in a non-endemic area: the experience of the Valencian Health Programme (Spain). Epidemiol Infect 2012;140:1896-903. 